\title{
VARIABILIDADE ESPACIAL DE ATRIBUTOS FÍSICOS DO SOLO EM UMA MICROBACIA HIDROGRÁFICA
}

\author{
Spatial variability of soil physical atribbutes in small watershed
}

\author{
Vinicius Augusto da Silveira Vieira ${ }^{1}$, Carlos Rogério de Mello², José Maria de Lima ${ }^{3}$
}

\begin{abstract}
RESUMO
A variabilidade espacial dos atributos físicos do solo é importante para a caracterização do comportamento espacial dos solos em bacias hidrográficas. Objetivou-se com este trabalho estudar a variabilidade espacial de atributos físicos do solo em uma microbacia hidrográfica, visando subsidiar estudos de manejo do solo e da água. A área em estudo é uma microbacia que pode ser considerada homogênea para estudos com agentes erosivos, como a precipitação, devido ao tamanho reduzido (1,23 ha), mas de grande variabilidade de respostas à erosão, em função dos atributos do solo, vegetação, histórico de uso e relevo. Com o auxílio de SIG, DGPS e estação total, toda área foi dividida em grid retangular de $20 \mathrm{~m}$, onde o solo foi amostrado em duas camadas, $0 \mathrm{a} 20 \mathrm{~cm}$ e $20 \mathrm{a} 40 \mathrm{~cm}$. Os atributos avaliados foram: teores de areia, silte e argila e argila dispersa em água (ADA). Os resultados foram analisados utilizando-se a estatística básica, como histogramas e assimetria, e geoestatística, por meio de semivariogramas e mapas de krigagem. Houve dependência espacial de todos os atributos analisados, especialmente na camada de 20 a $40 \mathrm{~cm}$.
\end{abstract}

Termos para indexação: Geoestatística, física do solo, microbacia hidrográfica.

\section{ABSTRACT}

The spatial variability of physical attributes in the soil is of great importance for soil and water management practices. This work aimed at to study the spatial variability of soil physical attributes in a small watershed, in order to evaluate the management of soil and water. The watershed area is considered homogenious, based on erosive agents, such as rainfall, due to its small area (1,23 ha), and it shows variability of soil properties, concerning vegetation, land use, and topography. GIS, DGPS and total station were used to set up a grid of $20 \times 20 \mathrm{~m}$. Soil were sampled from 0 to $20 \mathrm{~cm}$ and 20 to $40 \mathrm{~cm}$ layers. Amount of sandy, silt, clay and water dispersible clay were evaluated. The data were compared in histograms, coefficient of simetry, and geostatistical analyses expressed by semivariograms and kriging maps. All soil attributes demonstrated a spatial dependence, specially at $20-40 \mathrm{~cm}$ layer.

Index terms: Geostatistical, soil physical attributes, watershed.

(Recebido em 15 de julho de 2005 e aprovado em 29 de junho de 2006)

\section{INTRODUÇÃO}

A textura, um dos atributos mais estáveis do solo, é dependente do material originário e dos agentes naturais de formação do solo, sendo pouco alterada pelo cultivo ou outras práticas agrícolas. Entretanto, a erosão diferenciada pode promover, na camada superficial do solo, pequenas variações na proporção das frações granulométricas. Qualquer outra causa de variabilidade espacial na textura do solo se deve à variabilidade em material de origem ou a formação do solo.

0 conhecimento da variabilidade espacial de um solo, além de caracterizar uma região, gera uma estimativa do parâmetro sem viés, sendo possível planejar de maneira mais eficaz a implantação de malhas de amostragem (MULLA et al., 1992; ORTIZ, 2002; ROQUE, 2003).

A variabilidade espacial de atributos físicos dos solos em bacias hidrográficas tem sido objeto de alguns estudos nos últimos anos (VIEIRA, 1998). Segundo Burrough (1987), a variação espacial de uma variável regionalizada pode ser expressa pela soma de três componentes: a) uma componente estrutural, associada a um valor médio constante ou a uma tendência constante; b) uma componente aleatória, espacialmente correlacionada e c) um ruído aleatório ou erro residual.

De acordo com Guimarães (2000), para que a geoestatística possa ser usada, há necessidade de que pelo menos uma das duas hipóteses de estacionariedade de uma função aleatória Z(xi) seja satisfeita: a hipótese de estacionariedade de ordem 2 e a hipótese intrínseca. Além dessas hipóteses, deve-se obedecer a condição de não tendenciosidade para aplicação da teoria geoestatística. $\mathrm{O}$ Variograma ou semivariograma é uma ferramenta básica de suporte às técnicas de krigagem, que permite representar quantitativamente a variação de um fenômeno regionalizado no espaço (HUIJBREGTS, 1975).

\footnotetext{
'Engenheiro Agrônomo, M.Sc em Solos e Nutrição de Plantas - Universidade Federal de Lavras/UFLA - Cx. P. 3037 - $37200-000$ - Lavras, MG Bolsista FAPEMIG.

${ }^{2}$ Professor Adjunto, Departamento de Engenharia/DEG - Universidade Federal de Lavras/UFLA - Cx. P. 3037 - $37200-000$ - Lavras, MG crmello@ufla.br - Bolsista CNPq.

${ }^{3}$ Professor Adjunto, Departamento de Ciência do Solo/DCS - Universidade Federal de Lavras/UFLA - Cx. P. 3037 - $37200-000$ - Lavras, MG jmlima@ufla.br - bolsista CNPq.
} 
O procedimento de krigagem, segundo Isaaks \& Srivastava (1989), é semelhante ao de interpolação por média móvel ponderada, exceto que aqui os pesos são determinados a partir de uma análise espacial. A diferença entre a krigagem e outros métodos de interpolação é que, na krigagem, os pesos são determinados a partir de uma análise espacial baseada no semivariograma experimental. Além disso, a krigagem fornece, em média, estimativas não tendenciosas e com variância mínima (RIBEIRO JUNIOR, 1995).

O objetivo deste estudo foi avaliar a estrutura de continuidade espacial de atributos físicos do solo em uma microbacia hidrográfica de escoamento efêmero, visando estabelecer maior conhecimento espacial destes atributos físicos de solo estudados.

\section{MATERIAL E MÉTODOS}

A área é localizada no sul de Minas Gerais, a $11 \mathrm{~km}$ da cidade de Lavras, pertencente à Bacia Hidrográfica do Rio Grande, próximo à Usina Hidrelétrica do Funil, de coordenadas UTM $496.706 \mathrm{~m}$ a $496.846 \mathrm{~m}$, oeste de Greenwich e 7.658.207 m a 7.658.387 m Sul, fuso 45, 23K, DATUM Córrego Alegre. O clima da região é uma transição de Cwb para Cwa, pela classificação de Köppen (VILLELA \& RAMALHO, 1981). A microbacia apresenta área de 1,23 ha e perímetro de 448,93 metros. A maior parte da área vem sendo utilizada com pastagem plantada de Brachiaria decumbens e Paspalum notatum (grama batatais), Eucalyptus grandis, uma pequena área de vegetação típica de várzea em área de surgência e uma pequena mata de essências nativas plantadas há alguns anos (Figura 1).

Os solos da microbacia (Figura 2), constituem-se de Cambissolo Háplico Tb Distrófico, em sua maior parte, Argissolo Vermelho-Amarelo Distrófico Típico e Gleissolo Háplico Tb Distrófico. A declividade média da microbacia é de aproximadamente $30 \%$, variando de $0 \%$ a mais de $45 \%$. A amostragem foi realizada de forma sistemática em grid retangular regular. A escolha do formato retangular teve como propósito reduzir possíveis falhas no ajuste do modelo do semivariograma, evidenciado por Sales (1992). Marcou-se, em toda a área, um grid de 20 x 20 metros, com um adensamento de amostragem retangular, deslocado de 10 metros da malha principal. Formou-se uma malha de 56 pontos em duas camadas, de 0 a $20 \mathrm{~cm}$ (primeiro plano amostral) e 20 a $40 \mathrm{~cm}$ (segundo plano amostral), totalizando 112 amostras (Figura 3).

As análises físicas foram realizadas com o procedimento de rotina do laboratório de Física dos Solos do Departamento de Ciência do Solo da UFLA. A textura foi avaliada pelo método de Bouyoucos e o teor de argila dispersa em água (ADA), segundo Embrapa (1997).

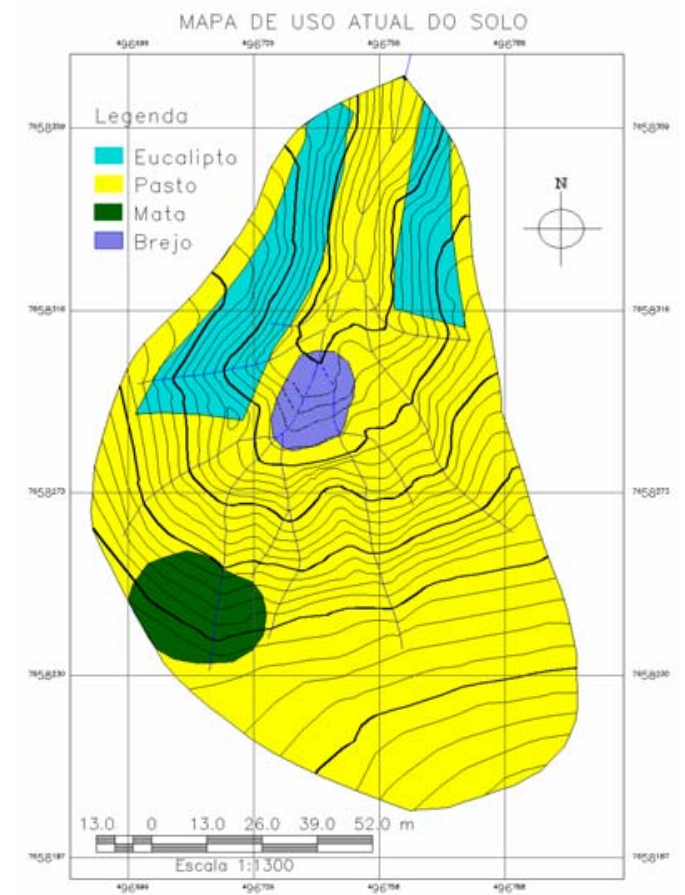

FIGURA 1 - Mapa de uso atual do solo da microbacia experimental.

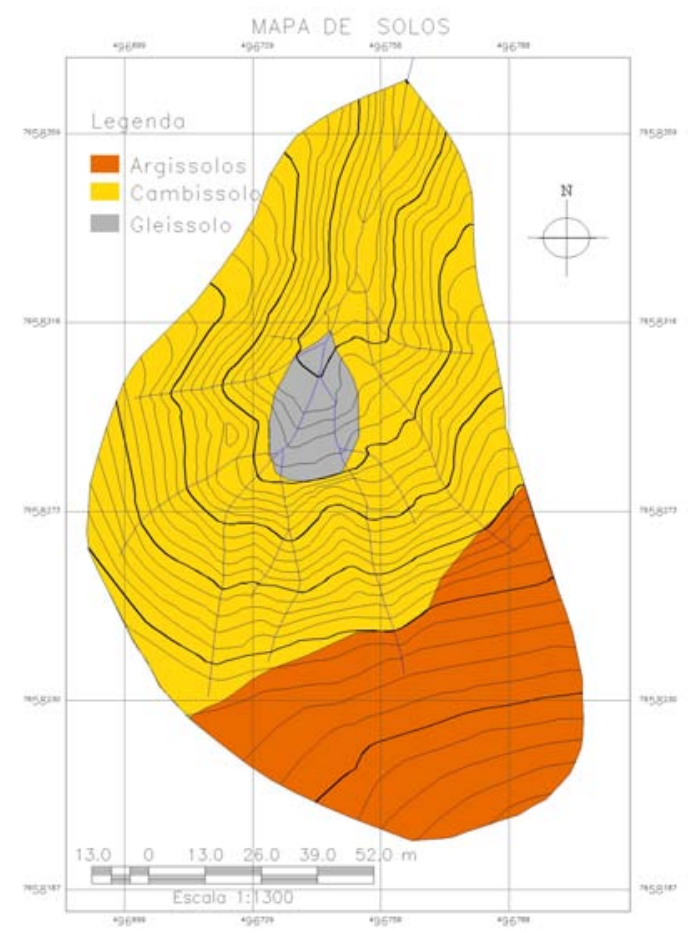

FIGURA 2 - Mapa de Classificação dos Solos da microbacia experimental. 
Foram determinados, para cada um dos atributos de solo estudados, a média, o desvio padrão, o coeficiente de variação da média e o coeficiente de assimetria. Adotouse os limites de coeficiente de variação (CV\%) propostos por Warrick \& Nielsen (1980) para a classificação de variáveis do solo sendo: baixa: $(\mathrm{CV} \%)<12 \%$; média: entre $12 \%$ e $60 \%$ e alta: $(\mathrm{CV} \%)>60 \%$.

A análise da distribuição dos dados foi feita com base na seguinte classificação: coeficiente de assimetria, $(\mathrm{CA})=0 ;$ (distribuição simétrica); $(\mathrm{CA})>0$; (distribuição assimétrica à esquerda) e (CA) < 0 ; (distribuição assimétrica à direita).

Para dependência espacial utilizou-se o método dos momentos (JOURNEL, 1989) e o grau de dependência espacial, a classificação de Cambardella et al. (1994).

Com os parâmetros estimados do semivariograma, foram ajustados modelos para se expressar a semivariância em função da distância, destacando-se os modelos esférico, gaussiano e exponencial. O ajuste dos modelos de semivariograma foi obtido com base nos métodos da Máxima Verossimilhança (ML) e ou Mínimos Quadrados Ponderados (MQP), no programa GeoR, analisando-se, posteriormente, o melhor ajuste obtido. Também foram obtidos os parâmetros de ajustes dos modelos, como: alcance (A), efeito pepita (EP) e contribuição (P-EP = patamar - efeito pepita). Os mapas de krigagem também foram gerados pelo software GeoR, considerando o melhor modelo de semivariograma obtido.

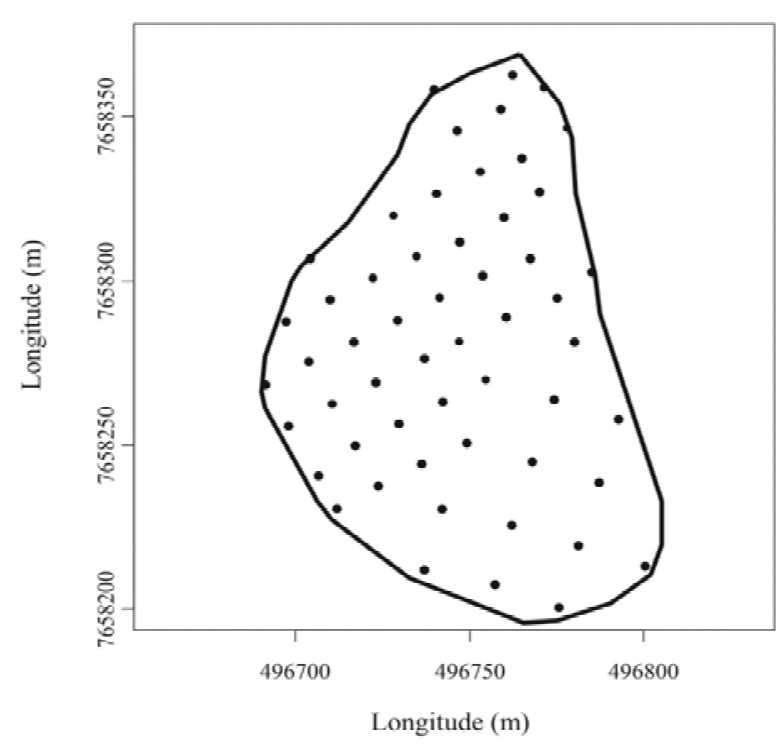

FIGURA 3 - Mapa com grid e pontos de amostragem na microbacia experimental.
No presente estudo, foram selecionados os atributos físicos do solo: teores de areia, silte e argila e argila dispersa em água (ADA) para a avaliação da variabilidade espacial na microbacia, nas camadas de 0 a $20 \mathrm{~cm}$ e 20 a $40 \mathrm{~cm}$.

\section{RESULTADOS E DISCUSSÃO}

$\mathrm{Na}$ Tabela 1 apresentam-se os resultados da estatística básica dos atributos físicos do solo, analisados para a camada de 0 a $20 \mathrm{~cm}$. O coeficiente de variação para teores de argila dispersa em água (ADA) também merece destaque, apresentando maior valor $(49,7 \%)$, entre as demais variáveis que apresentaram $(\mathrm{CV} \%)$ médios.

Ao se analisar a coluna do coeficiente de assimetria (CA), (Tabela 1), observa-se que as variáveis areia, argila e silte produziram assimetrias menores que 1 , sendo estes os atributos que apresentaram maior proximidade com a distribuição normal. Vale destacar que, o teor de argila apresenta assimetria negativa, ou seja, teve seus dados levemente concentrados à direita; para os teores de silte $\mathrm{e}$ areia, a assimetria é positiva, com maior acúmulo dos dados à esquerda, apresentando leve assimetria. $\mathrm{O}$ atributo (ADA) produziu elevado coeficiente de assimetria, sendo de distribuição assimétrica.

Na Tabela 2 têm-se as estatísticas básicas dos atributos físicos para a camada de 20 a $40 \mathrm{~cm}$. Destaca-se que a (ADA) apresenta valores pouco menores que na camada de 0 a $20 \mathrm{~cm}$, mesmo assim, ainda pode ser considerada média a alta.

TABELA 1 - Estatística básica dos atributos estudados na camada de 0 a $20 \mathrm{~cm}$.

\begin{tabular}{lcccc}
\hline Variáveis & Média & Desvio & CV $(\%)$ & CA \\
\hline Areia & 49,63 & 8,40 & 16,9 & 0,384 \\
Silte & 23,33 & 5,162 & 22,1 & 0,298 \\
Argila & 27,43 & 4,99 & 18,2 & $-0,182$ \\
ADA & 11,06 & 5,50 & 49,7 & 3,758 \\
\hline
\end{tabular}

TABELA 2 - Estatística básica dos atributos do solo na camada de 20 a $40 \mathrm{~cm}$.

\begin{tabular}{ccccc}
\hline Variáveis & Média & Desvio & CV (\%) & CA \\
\hline Areia & 47,34 & 8,52 & 18,0 & 0,663 \\
Silte & 25,64 & 4,24 & 16,6 & 0,0015 \\
Argila & 27,29 & 6,14 & 22,5 & $-0,22$ \\
ADA & 13,38 & 4,83 & 36,1 & 0,836 \\
\hline
\end{tabular}


Juntamente com os dados da coluna do coeficiente de assimetria (CA), na Tabela 2, camada de 20 a $40 \mathrm{~cm}$, é possível verificar o nível de dispersão em torno do valor central. Os atributos teores de silte, areia e argila apresentaram menores coeficientes, possuindo tendência à distribuição normal, com alguns coeficientes consideravelmente pequenos (teores de silte e de argila). De maneira geral, os dados da Tabela 2, mostram tendência à menor distorção e maior normalidade. Espera-se que, para estes dados, sejam possíveis ajustes do semivariograma de forma mais estruturada. Os teores de argila dispersa em água (ADA) produziram assimetria positiva na camada de 20 a $40 \mathrm{~cm}$, maior que na camada superior, com elevada concentração da frequiência à esquerda. Houve redução considerável do coeficiente de assimetria dos atributos (ADA) e silte.

Este comportamento dos atributos estudados, em função da camada pode ser explicado com base na classe de solo predominante e suas características. A classe de solo dominante na área da microbacia experimental é o Cambissolo. Neste caso, a presença de horizonte B incipiente, ou mesmo a transição entre horizonte $\mathrm{B}$ e $\mathrm{C}$ na camada de 20 a $40 \mathrm{~cm}$, podem justificar a elevada variabilidade nos teores de silte e nos demais parâmetros estudados. Quanto menos intemperizado o material do solo, maior a tendência de variação. Outra causa de grande variabilidade dos atributos do solo está relacionada com a mudança no material de origem.

Na Tabela 3 são apresentados os ajustes de semivariograma para os atributos físicos estudados, para os solos da microbacia hidrográfica experimental. Analisase também a predominância da metodologia dos Mínimos Quadrados Ponderados (MPQ) sobre a máxima verossimilhança (ML). Isto se deve ao fato de que a máxima verossimilhança se ajusta às diferenças quadráticas dos dados brutos e não aos pontos do semivariograma, estando intimamente relacionada à normalidade das semivariâncias (MELLO, 2004; RIBEIRO JÚNIOR \& DIGGLE, 2001).
O atributo teor de areia apresentou $100 \%$ de dependência espacial, ou seja, dentro dos limites do alcance, a maior parte da variabilidade pode ser explicada pela componente espacial. Esse valor pode representar efeito pepita nulo, obtido pela metodologia dos Mínimos Quadrados Ponderados, para o modelo exponencial. É importante destacar que nenhum dos atributos apresentou grau de dependência menor que $50 \%$, ou seja, segundo Cambardella et al. (1994), no mínimo, há tendência mediana de influência da componente espacial.

Deve também ser mencionado que o semivariograma do atributo teor de silte apresentou alcance superior a $100 \mathrm{~m}$. Isto significa que, em qualquer ponto na microbacia hidrográfica, haverá dependência espacial destes atributos em relação a quaisquer outros pontos, uma vez que o patamar dos mesmos somente será obtido a uma distância superior à máxima distância possível na microbacia. Então, para estes atributos, o grid amostral adotado poderia ser superior a $20 \mathrm{~m}$, até os limites da microbacia, sendo mantida sua dependência espacial. Para os demais atributos, o alcance é inferior ao máximo comprimento da microbacia e superior a 20 metros. Segundo Ortiz (2002), o conhecimento da variabilidade espacial de um solo, além de caracterizar uma região, pode indicar o número e a distribuição de amostras a serem retiradas, possibilitando melhor detalhamento da área e dos resultados. Na Figura 4, apresentam-se os semivariogramas ajustados.

$\mathrm{Na}$ Tabela 4, observam-se os atributos na camada de 20 a $40 \mathrm{~cm}$. Verifica-se que um maior número de atributos possui forte tendência à explicação do comportamento de sua variabilidade pela componente espacial, há um ganho considerável de estruturação na dependência espacial nesta camada, para os atributos teores de argila e silte. Em contrapartida, verifica-se perda de dependência espacial do atributo ADA. Os semivariogramas ajustados estão apresentados na Figura 5.

TABELA 3 - Características dos semivariogramas ajustados para os atributos estudados na camada de 0 a $20 \mathrm{~cm}$.

\begin{tabular}{|c|c|c|c|c|c|c|}
\hline \multirow[t]{2}{*}{ Atributos } & \multirow{2}{*}{ Modelo } & \multicolumn{3}{|c|}{ Parâmetros de Ajuste } & \multirow[t]{2}{*}{ Método de ajuste } & \multirow[t]{2}{*}{ GD } \\
\hline & & $\mathbf{A}$ & EP & $\mathbf{P}$ & & \\
\hline Areia & Exponencial & 25,04 & 0 & 75,73 & MQP & $100 \%$ \\
\hline Argila & Esférico & 85,9 & 14,94 & 28,28 & MQP & $65 \%$ \\
\hline Silte & Exponencial & 109,3 & 11,61 & 30,06 & MQP & $72 \%$ \\
\hline ADA & Exponencial & 91,77 & 0 & 47,44 & MQP & $100 \%$ \\
\hline
\end{tabular}

$\mathrm{A}=$ alcance $(\mathrm{m}) ; \mathrm{EP}=$ efeito pepita; $\mathrm{P}=$ patamar; $\mathrm{ML}=$ máxima verossimilhança; $\mathrm{MQP}=$ mínimos quadrados ponderados e GD = grau de dependência espacial. 

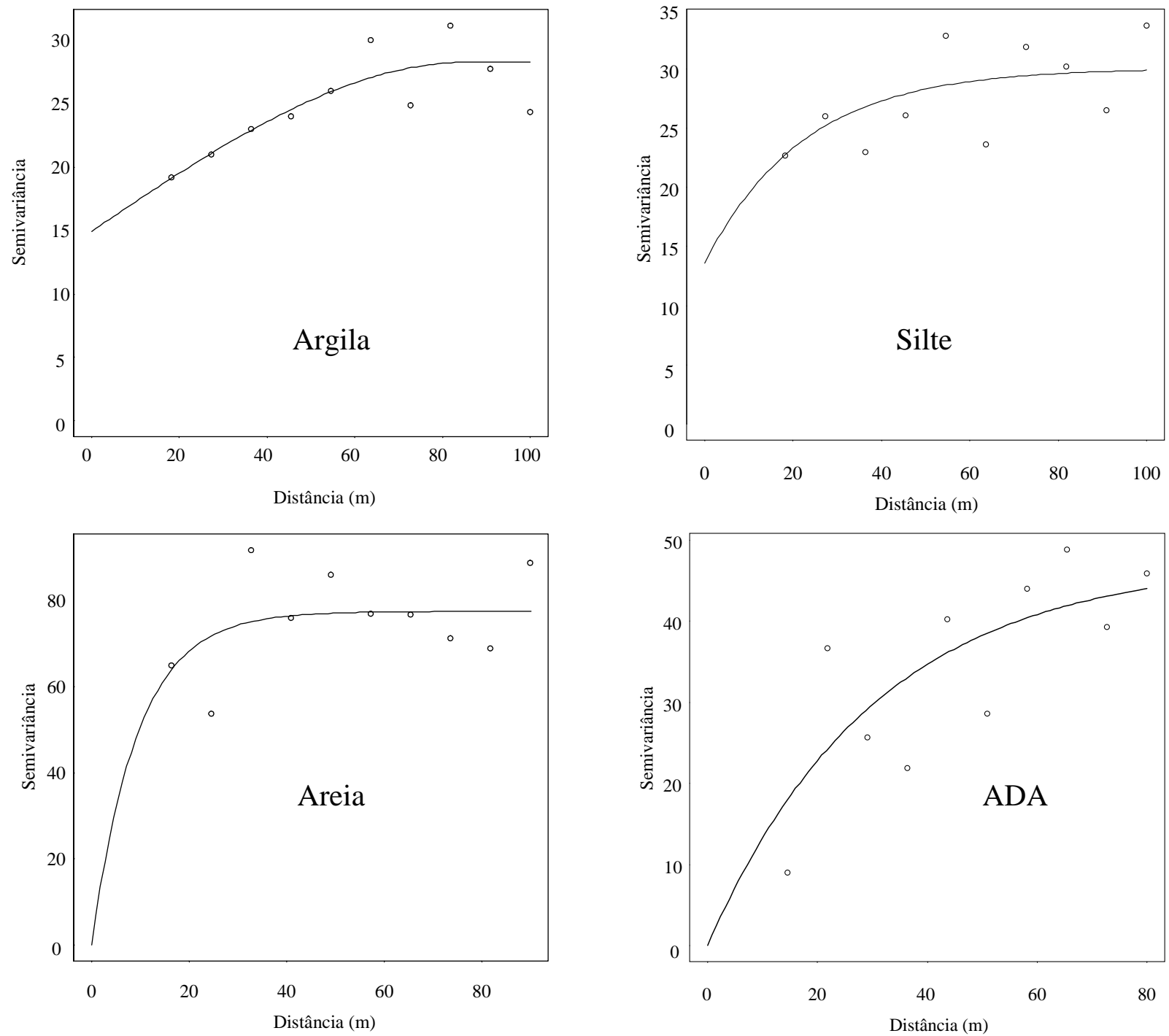

FIGURA 4 - Semivariogramas ajustados dos atributos argila, (ADA), silte e areia na camada de 0 a $20 \mathrm{~cm}$.

TABELA 4 - Características dos semivariogramas ajustados para os atributos estudados na camada de 20 a $40 \mathrm{~cm}$.

\begin{tabular}{llrrrrrr}
\hline \multirow{2}{*}{ Atributos } & Modelo & \multicolumn{3}{c}{ Parâmetros de Ajuste } & \multirow{2}{*}{ Método de ajuste } & GD \\
\cline { 3 - 5 } & & A & EP & P & & \\
\hline Areia & Exponencial & 37,5 & 0 & 80,81 & & MQP & $100 \%$ \\
Argila & Exponencial & 42,03 & 0 & 43,37 & & MQP & $100 \%$ \\
Silte & Exponencial & 59,58 & 0 & 21,27 & & MQP & $100 \%$ \\
ADA & Exponencial & 41,1 & 12,91 & 23,26 & & MQP & $64,31 \%$ \\
\hline
\end{tabular}

$\mathrm{A}=$ alcance $(\mathrm{m}) ; \mathrm{EP}=$ efeito pepita; $\mathrm{P}=$ patamar; $\mathrm{ML}=$ máxima verossimilhança; $\mathrm{MQP}=$ mínimos quadrados ponderados e GD = grau de dependência espacial. 

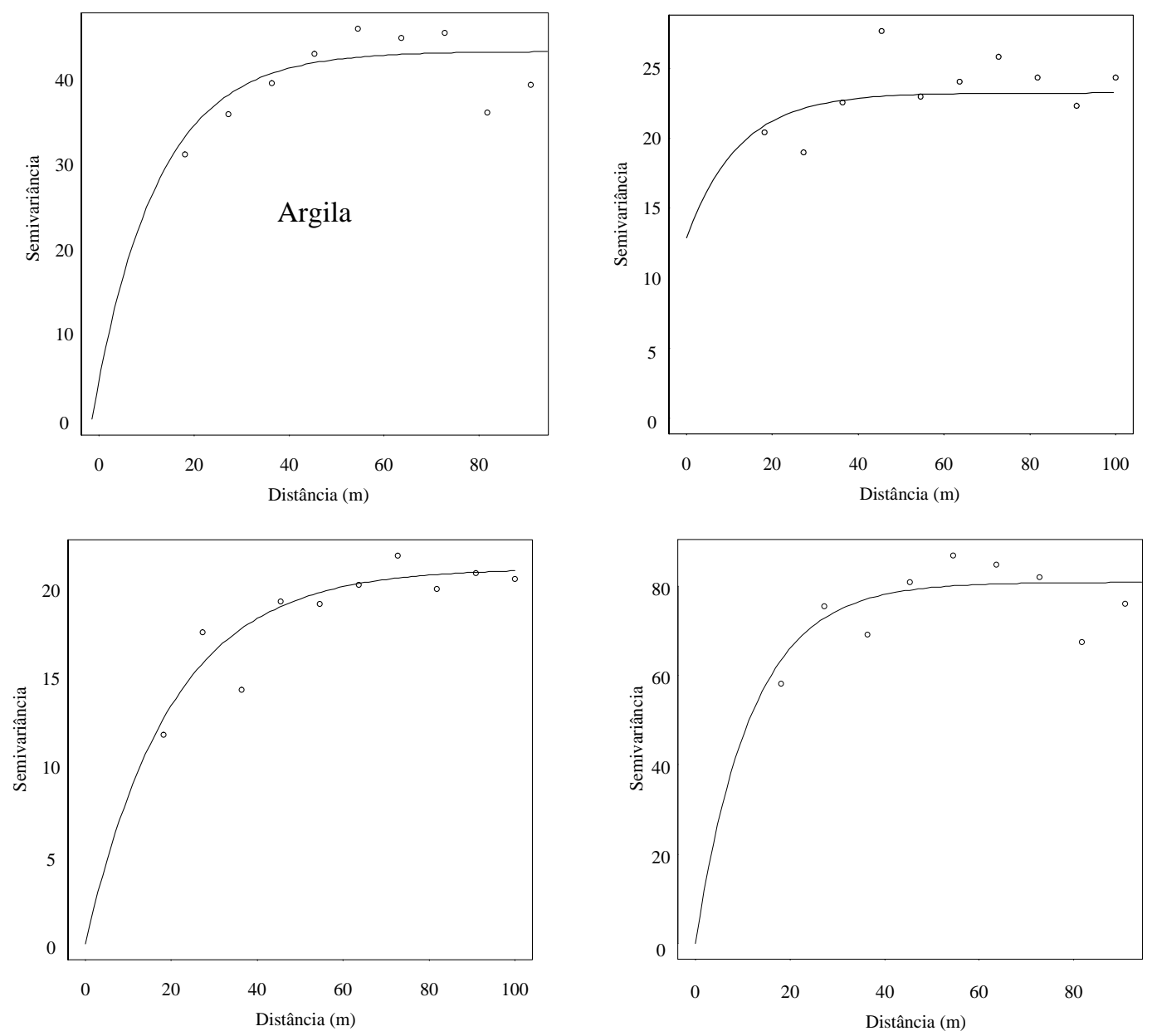

FIGURA 5 - Semivariogramas ajustados aos atributos argila, (ADA), silte e areia na camada de 20 a $40 \mathrm{~cm}$.

Observa-se, para a primeira camada, uma tendência de aumento do teor de areia no sentido oeste-leste e sulnorte da microbacia, havendo pontos na região de surgência (várzea) com valores mais elevados (áreas mais claras), (Figura 6). Estes pontos parecem caracterizar uma região de recebimento de sedimentos de diferentes granulometrias e, por se tratar de área acima do ponto mais baixo da bacia, ainda está sujeita ao processo de remoção, desta vez de partículas mais finas, por se tratar de uma área mais plana onde a velocidade de enxurrada não chega a ser suficiente para dar continuidade à remoção de sedimentos mais grosseiros (areia), ficando esse material depositado. De forma contrária, verifica-se aumento do teor de silte no sentido leste-oeste, com área de maior percentual ocupando mais da metade da microbacia, (Figura 7). O teor de argila (Figura 8), em contrapartida, possui os maiores percentuais na região leste, podendo-se observar um leve gradiente negativo no sentido norte-sul. Na camada de 20 a $40 \mathrm{~cm}$, é possível observar redução geral do teor de argila, em que a camada de 0 a $20 \mathrm{~cm}$ apresenta amplitude de 40 a $70 \%$ nos teores de argila e a camada de 20 a $24 \mathrm{~cm}$ varia de 10 a $40 \%$. Os teores de silte são maiores em profundidade, havendo áreas mais claras em relação à camada superficial, sendo esta uma característica fundamental dos Cambissolos (RESENDE et al., 1999).

Comportamento semelhante ao do silte pode ser constatado para o teor de argila, para o qual há aumento das áreas mais claras em relação à superfície, especialmente na parte sul da microbacia, onde há predominância de Argissolo, cuja principal característica é o aumento do teor de argila em profundidade (RESENDE et al., 1999). 
Os menores teores de silte relativamente aos maiores teores de argila apontam para um material mais intemperizado e, conseqüientemente, com argilas de menor atividade. Nesta camada (20 a $40 \mathrm{~cm}$ ) verifica-se pequeno gradiente do teor de argila em direção ao sul, noroeste e ao norte.

Na Figura 9 apresentam-se os mapas de krigagem do atributo Argila Dispersa em Água (ADA). É possível
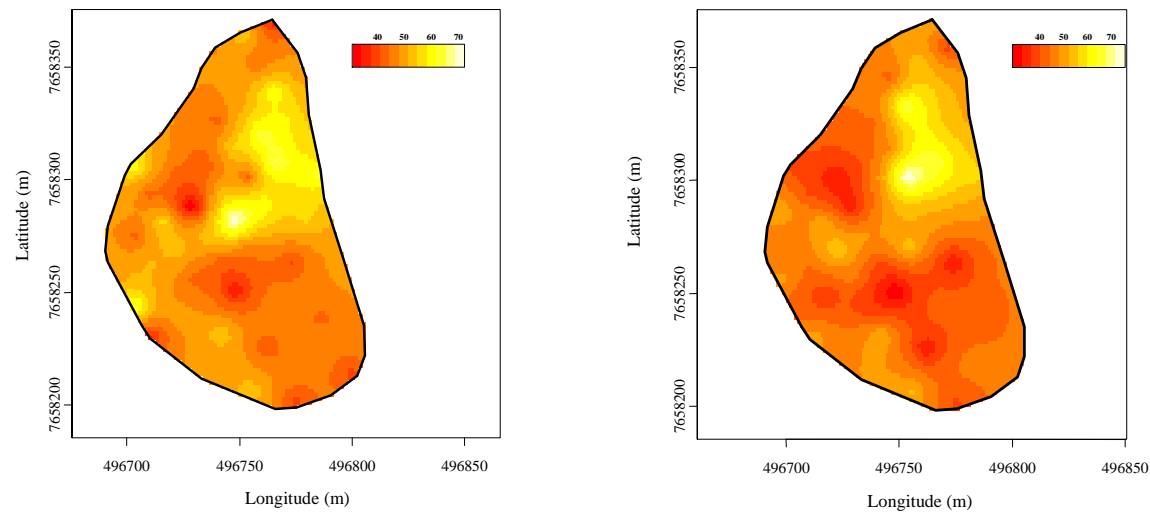

FIGURA 6 - Mapas de krigagem do Teor de Areia, nas camadas de 0 a $20 \mathrm{~cm}$ (esquerda) e 20 a $40 \mathrm{~cm}$ (direita).
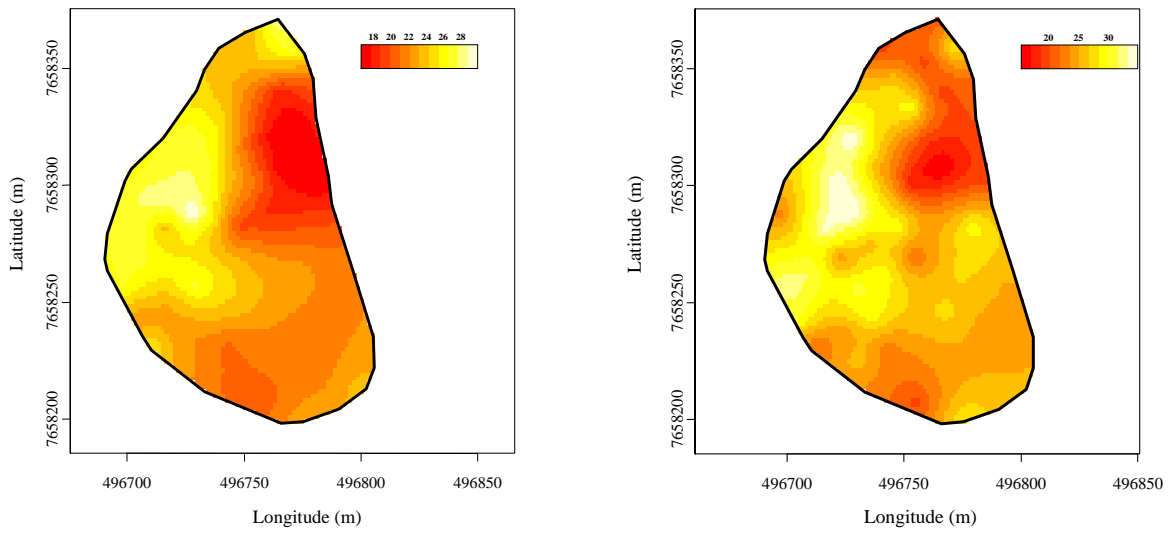

FIGURA 7 - Mapas de krigagem do Teor de Silte, nas camadas de 0 a $20 \mathrm{~cm}$ (esquerda) e 20 a $40 \mathrm{~m}$ (direita).
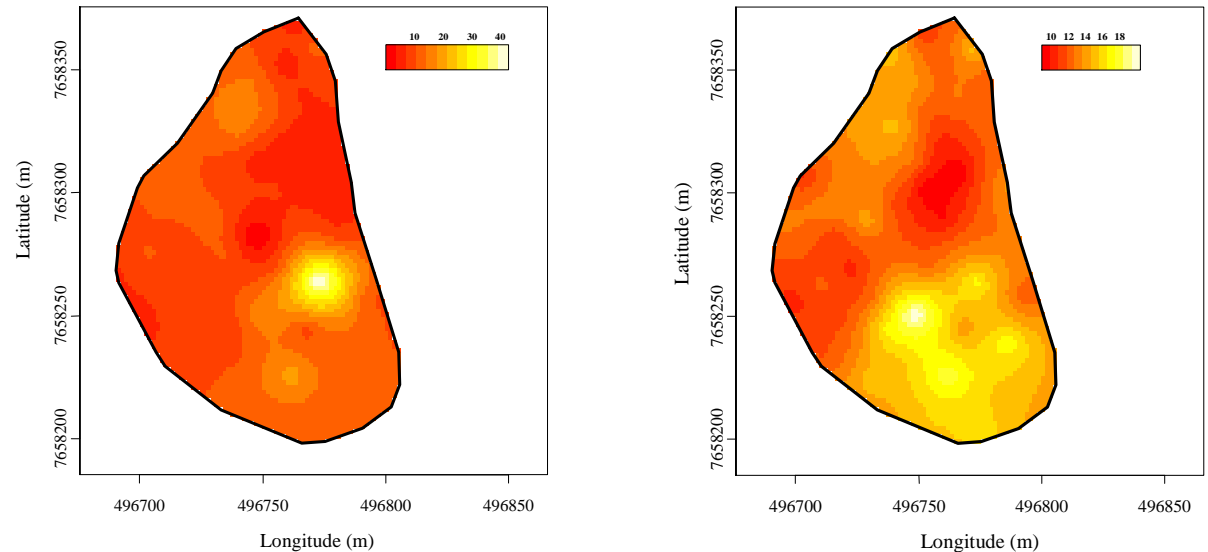

FIGURA 8 - Mapas de krigagem do Teor de Argila, nas camadas de 0 a $20 \mathrm{~cm}$ (esquerda) e 20 a $40 \mathrm{~cm}$ (direita). 

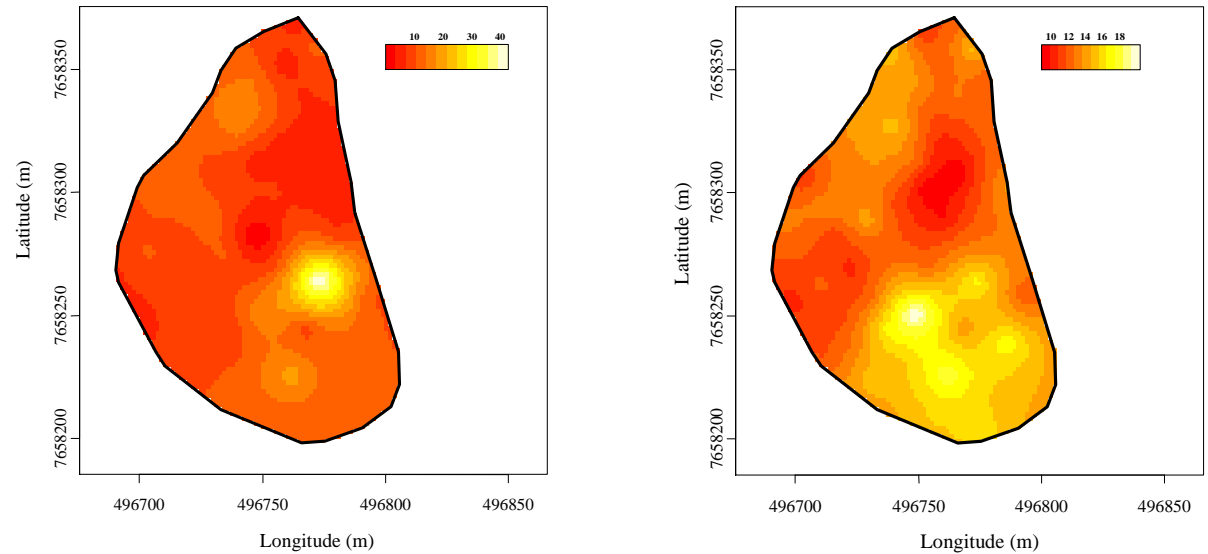

FIGURA 9 - Mapas de krigagem de Argila Dispersa em Água (ADA), nas camadas de 0 a 20 (esquerda) e 20 a $40 \mathrm{~cm}$ (direita).

verificar que os maiores valores deste atributo ocorreram nas regiões sul e noroeste da micro bacia, especialmente na primeira camada. De forma comparativa, verifica-se maior concentração de argila nesta região, especialmente de 20 a $40 \mathrm{~cm}$ o que pode implicar, em termos de proporção, maiores valores de ADA. Verifica-se também que na camada de 20 a $40 \mathrm{~cm}$ há valores consideravelmente superiores que na camada de 0 a $20 \mathrm{~cm}$, principalmente, na parte sul da microbacia, devido, principalmente, à presença de Argissolos nesta posição.

\section{CONCLUSÕES}

Todos os atributos estudados apresentaram dependência espacial, demonstrando que o grid retangular de $20 \times 20 \mathrm{~m}$ foi suficiente para os estudos propostos, especialmente para a camada de $20-40 \mathrm{~cm}$. Verificou-se influência da posição no relevo e a declividade na variabilidade espacial dos teores de areia, silte e argila quando se considera o mesmo material de origem. Analisando-se o comportamento espacial dos mapas de krigagem dos teores de argila, silte, ADA e o mapa de declividade da microbacia, consegue-se definir os limites exatos entre o Cambissolo e o Argissolo.

\section{REFERÊNCIAS BIBLIOGRÁFICAS}

BURROUGH, P. A. Principles of geographical information systems for land resources assessment. Oxford: Clarendon, 1987. 193 p.

CAMBARDELLA, C. A.; MOORMAN, T. B.; NOVAK, J. M.; PARKIN, T. B.; KARLEN, D. L.; TURCO, R. F.;
KONOPKA, A. E. Field-scale variability of soil properties in Central lowa Soils. Soil Science Society of America Journal, Madison, v. 58, n. 5, p. 1501-1511, Sept./Oct. 1994.

EMPRESA BRASILEIRA DE PESQUISA AGROPECUÁRIA. Manual de métodos de análises do solo. 2. ed. Rio de Janeiro: Ministério da Agricultura e do Abastecimento, 1997. 212 p.

GUIMARÃES, E. C. Variabilidade espacial de atributos de uma Latossolo Vermelho Escuro textura argilosa da região do cerrado, submetido ao plantio direto e ao plantio convencional. 2000. 85 f. Tese (Doutorado) - Universidade de Campinas, Campinas, 2000.

HUIJBREGTS, C. J. Regionalized variables and quantitative analysis of spatial data. In: DAVIS, J. C.; McCULLAGH, M. J. (Eds.). Display and analysis of spatial data. New York: J. Wiley, 1975. p. 38-53.

ISAAKS, E. H.; SRIVASTAVA, R. M. An introduction to applied geoestatistics. New York: Oxford University, 1989. $561 \mathrm{p}$.

JOURNEL, A. G. Fundamentals of geostatistics in five lessons. Washington: American Geophysical Union, 1989. $40 \mathrm{p}$.

MELLO, J. M. Estatística espacial aplicada ao inventário florestal. 2004. 150 f. Tese (Doutorado em Ciências Florestais) - Escola Superior de Agricultura Luiz de Queiroz, Piracicaba, 2004. 
MULLA, D. J.; BATÍ, A. U.; HAMMOND, M. W.; BENSON, J. A. A comparison of winter wheat yield and quality under uniform versus spatially variable fertilizer management. Agriculture Ecosystems \& Environment, Amsterdam, v. 38, n. 4, p. 301-311, Mar. 1992.

ORTIZ, G. C. Aplicacação de métodos geoestatisticos para identificar a magnitude e a estrutura da variabilidade espacial de variaveis fisicas do solo. 2002.75 f. Dissertacão (Mestrado) - Escola Superior de Agricultura Luiz de Queiroz", Piracicaba, 2002.

RESENDE, M.; CURI, N.; REZENDE, S. B. de; CORREAA, G. F. Pedologia. 3. ed. Viçosa: NEPUT, 1999. 338 p.

RIBEIRO JÚNIOR, P. J. Métodos geoestatísticos no estudo da variabilidade espacial de parâmetros do solo. 1995. $99 \mathrm{f}$. Dissertação (Mestrado) - Escola Superior de Agricultura Luiz de Queiroz, Piracicaba, 1995.

RIBEIRO JUNIOR, P. J.; DIGGLE, P. J. GeoR: a package for geostatistical analysis. R News, London, v. 1, n. 2, p. 15-18, 2001.
ROQUE, M. W. Variabilidade espacial de atributos físicohídricos em solos de uma transeção perpendicular a um dreno natural. 2003. 138 p. Dissertação (Mestrado) Universidade Federal de Lavras, Lavras, 2003.

SALES, L. E. O. Variabilidade especial da velocidade de infiltração básica associada a propriedades físicas das camadas superficial e subsuperficial de dois solos da região de Lavras (MG). 1992. 103 f. Dissertação (Mestrado) - Escola Superior de Agricultura de Lavras, Lavras, 1992.

VIEIRA, S. R. Geoestatística aplicada à agricultura de precisão. In: GIS Brasil'98. Curitiba: [s.n.], 1998. $53 \mathrm{p}$.

VILELA, E. A.; RAMALHO, M. A. P. Análise das temperaturas e precipitações pluviométricas de Lavras-MG. Ciência e Prática, Lavras, v. 3, n. 6, p. 71-79, nov./dez. 1981.

WARRICK, A. W.; NIELSEN, D. R. Spatial variability of soil physical properties in the field. In: HILLEL, D. (Ed.). Applications of soil physics. New York: Academic, 1980. 